\title{
Analytical Electron Microscopy Investigation of Topologically Close-Packed Phases in CMSX-4 Single Crystal Superalloy
}

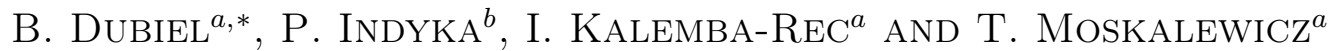 \\ ${ }^{a}$ AGH University of Science and Technology, Faculty of Metals Engineering and Industrial Computer Science, \\ al. A. Mickiewicza 30, 30-059 Kraków, Poland \\ ${ }^{b}$ Jagiellonian University, Faculty of Chemistry, R. Ingardena 3, 30-060 Kraków, Poland
}

\begin{abstract}
In this work the topologically close-packed phases precipitated during annealing of CMSX-4 single-crystal superalloy at temperature $1100^{\circ} \mathrm{C}$ were investigated. Microstructural analyses were carried out by means of scanningand transmission electron microscopy as well as scanning-transmission electron microscopy in high angle annular dark field mode. Chemical composition in nanoareas was determined using energy dispersive X-ray spectroscopy. Scanning electron microscopy investigation has shown that the topologically close-packed precipitates were formed already after $50 \mathrm{~h}$ of annealing at temperature $1000^{\circ} \mathrm{C}$. With prolongation of the annealing time up to $2500 \mathrm{~h}$ the change of the morphology of topologically close-packed particles from blocky to needle-like occurred. Selected area electron diffraction analysis indicated that the topologically close-packed precipitates are the orthorhombic $\mathrm{P}$ phase. Quantitative energy dispersive X-ray spectroscopy analysis revealed that the topologically close-packed precipitates are enriched mostly in Re and W.
\end{abstract}

DOI: 10.12693/APhysPolA.130.1110

PACS/topics: 61.66.Dk, 68.37.Hk, 68.37.Lp, 68.37.Ma, 82.80.Ej, 61.05.J-

\section{Introduction}

Single crystal Ni-base superalloys are widely used for turbine blades in aircraft engines and stationary gas turbines. Their chemical composition undergoes modifications leading to the increase of their working temperature as well as improvement of creep, fatigue and corrosion resistance. The development of the new generations of single crystal superalloys is related with the addition of elements which slowly diffuse in nickel, like $\mathrm{Cr}, \mathrm{W}, \mathrm{Mo}$, $\mathrm{Re}$, and $\mathrm{Ru}[1-4]$. However, the creep properties of superalloys containing high amounts of refractory elements decrease due to formation of the intermetallic topologically close-packed phases, known as TCP [1-8]. The TCP phases which were reported to be precipitated in single crystal superalloys are: $\sigma$ (tetragonal, $P 42 / \mathrm{mnm}$ ), $\mu$ (trigonal, $R-3 m$ ), $\mathrm{P}$ (orthorhombic, Pnma) and R (rhombohedral, $P-31 \mathrm{~m})$ phases $[1,5,6]$.

The present work concerns the investigation of TCP phases in a commercial second generation single crystal superalloy CMSX-4 subjected to high temperature annealing at $1100^{\circ} \mathrm{C}$. The microstructure of CMSX-4 superalloy in as-received condition consists of $\gamma$ and $\gamma^{\prime}$ phases. The cuboidal precipitates of $\gamma^{\prime}$ phase $\left(\mathrm{Ni}_{3} \mathrm{Al}-\right.$ based, space group $P m 3 m$ ) are coherent with the $\gamma$ phase matrix (Ni-based solid solution, space group $F m 3 m$ ), which presents in the form of narrow channels, separating the precipitates. Many studies have been carried out on the characterisation of TCP phases in CMSX-4 superalloy [7-10]. Saunders et al. [7] have reported that in CMSX- $4 \sigma$ phase can be formed at temperature below

\footnotetext{
* corresponding author; e-mail: bdubiel@agh.edu.pl
}

$950^{\circ} \mathrm{C}$, while at higher temperature $\mu, \mathrm{P}$ and $\mathrm{R}$ phases are formed. They have pointed out that even the small changes in the Re, $\mathrm{W}$, or Cr concentration in the microareas can result in the formation of any of the possible TCP phases. Chmiela and co-authors [8] have investigated the TCP formation in single crystal CMSX-4 superalloy after long-time high temperature exposure at $1050^{\circ} \mathrm{C}$ and $1100^{\circ} \mathrm{C}$. They have observed the presence of both $\sigma$ and $\mathrm{P}$ phases. In the CMSX-4 creep deformed at the temperature range from $950^{\circ} \mathrm{C}$ to $1050^{\circ} \mathrm{C}$ Cheng et al. [9] and Choi et al. [10] have observed the $\mu$ phase. Chemical composition of the TCP phases in CMSX-4 superalloys was examined mainly by conventional energy-dispersive Xray spectrometry (EDS) in scanning- (SEM) or scanningtransmission electron microscopy (STEM) modes $[8,9]$. Due to the limits of EDS, the accuracy of the quantitative microanalysis was relatively low, and therefore the results should be regarded as approximate values. Recently, the advances in analytical electron microscopy enabled to perform both microstructural analysis and EDS microanalysis with high spatial resolution. However, there are no reports so far on quantitative EDS microanalysis of phases present in CMSX-4 superalloy performed using a new technology incorporating four silicon drift detector (SDD) system. Therefore in this work the microstructure and chemical composition of as-received CMSX-4 as well as annealed at temperature $1100^{\circ} \mathrm{C}$ was investigated using STEM and modern high spatial resolution and high efficiency EDS microanalysis.

\section{Materials and experimental}

The investigation has been performed using CMSX-4 single crystal superalloy delivered by Howmet Ltd, UK, 
in the form of $\langle 001\rangle$ oriented bars. Chemical composition of the alloy is following (in wt $\%$ ): $\mathrm{Ni}-9.5 \mathrm{Co}-6.4 \mathrm{Cr}-$ $6.4 \mathrm{Ta}-6.4 \mathrm{~W}-5.6 \mathrm{Al}-2.9 \mathrm{Re}-1 \mathrm{Ti}-0.6 \mathrm{Mo}-0.1 \mathrm{Hf}$. The superalloy was received after standard heat treatment. To investigate the microstructural changes caused by the high temperature exposure, the specimens cut perpendicular to [001] crystallographic direction in the single crystal were isothermally annealed at temperature $1100^{\circ} \mathrm{C}$ for the duration 500, 1000, and $2500 \mathrm{~h}$ and subsequently cooled in air. Microstructural investigation was carried out using SEM, TEM, and STEM. SEM analysis was performed using FEI Nova NanoSEM 450 microscope equipped with EDS spectrometer of EDAX. Thin foils for TEM analysis were prepared by ion beam milling using the Gatan PIPS. TEM investigation was performed using JEOL JEM-2010 ARP microscope. Specimens for STEM and EDS analysis were prepared by focused ion beam (FIB) milling with use of FEI QUANTA 3D 200i. STEM analysis in high angle annular dark-field (HAADF) have been carried out by means of FEI Tecnai Osiris microscope equipped with X-FEG high brightness electron source and Super-X EDS system of four SDD detectors. EDS maps were acquired in STEM mode with the resolution $1024 \times 1024$ pixels and the pixel size of $2 \mathrm{~nm}$. The
EDS data were stored for every point in the scanned area, which enabled to quantify the spectra at each point and thus to reconstruct the quantitative EDS maps and line profiles. Such reconstruction was carried out with the averaging of 5 pixels, which corresponds to $10 \mathrm{~nm} \times 10 \mathrm{~nm}$ square units. Based on the results of quantitative EDS analysis the average chemical composition of $\gamma, \gamma^{\prime}$ and TCP phases was determined.

\section{Results and discussion}

Figure 1 shows the STEM-HAADF image of the asreceived CMSX-4 superalloy microstructure with the corresponding EDS maps. The contrast intensity of STEMHAADF images is closely related to the atomic number $Z$, being approximately proportional to $Z^{2}$. The intensity of the $\gamma$ phase in Fig. 1 is brighter, because it contains chemical elements with higher mean atomic number than $\gamma^{\prime}$ cuboidal precipitates. EDS maps Co, Cr, Re, Mo, and W show higher intensity in the $\gamma$ phase, thus these elements partition to the $\gamma$ channels. The intensity of $\mathrm{Al}$, $\mathrm{Ti}$, Ta and Ni maps in the $\gamma^{\prime}$ phase indicates that their concentration is higher than in $\gamma$ phase.
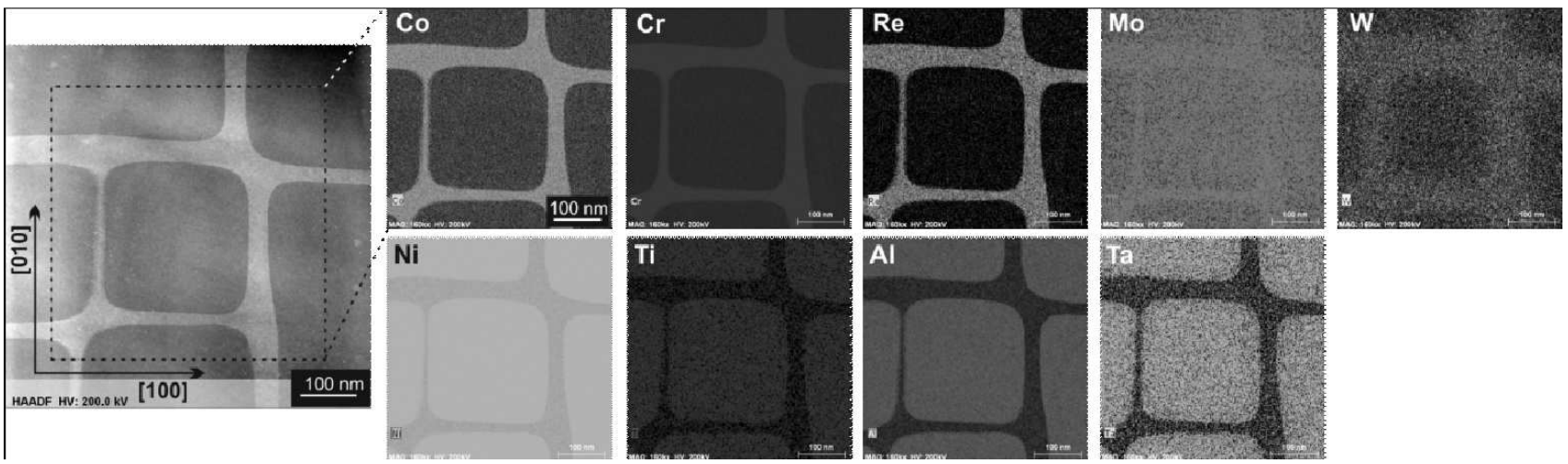

Fig. 1. STEM-HAADF image of the microstructure of CMSX-4 superalloy in as-received condition and EDS maps of chemical elements distribution in $\gamma$ and $\gamma^{\prime}$ phases.
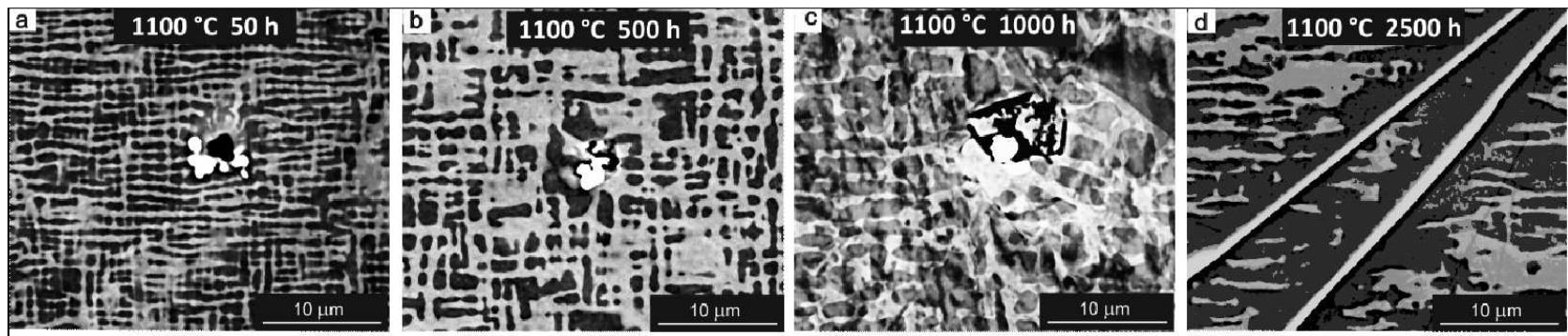

Fig. 2. SEM images of the CMSX-4 superalloy microstructure after annealing at temperature $1100{ }^{\circ} \mathrm{C}$ for (a) $50 \mathrm{~h}$, (b) $500 \mathrm{~h}$, (c) $1000 \mathrm{~h}$, (d) $2500 \mathrm{~h}$.

Figures $2 \mathrm{a}-\mathrm{c}$ show the SEM images of the microstructure of CMSX-4 after annealing at temperature $1100^{\circ} \mathrm{C}$ for $50,500,1000$, and $2500 \mathrm{~h}$. The changes in morphol- ogy of the $\gamma, \gamma^{\prime}$ and TCP phases with the annealing time can be observed. As it can be seen at SEM images, during the high temperature annealing the coalescence of 
cuboidal $\gamma^{\prime}$ precipitates occurred and the continuity of the $\gamma$ phase channels was destroyed. The thinner parts of $\gamma$ phase were dissolved, which resulted in the formation of irregular scaffold of continuous wavy channels as well as isolated $\gamma$ islands. After 50, 500, and $1000 \mathrm{~h}$ of annealing the TCP precipitates exhibited the blocky morphology in plane sections of $(001)_{\gamma}$. The presence of pores in the vicinity of TCP particles was observed. EDS microanalysis in SEM revealed that blocky precipitates contain Re, W, and Mo. With prolongation of the annealing time up to $2500 \mathrm{~h}$ the morphology and chemical composition of the TCP precipitates have changed and the needle-like particles rich in Re, W, Mo, Co, and $\mathrm{Cr}$ were present. Around the TCP phases the dissolution of the $\gamma$ phase was observed. It suggests that the TCP phase grow by the uptake of the $\gamma$-phase forming elements. Compared to blocky morphology, the needle-like precipitates of TCP phases are more intensively investi- gated due to their potential influence on shortening creep life-time of single-crystal superalloys $[8,9]$. Therefore the more detailed analysis of TCP phases were performed for the CMSX-4 annealed at temperature $1100^{\circ} \mathrm{C}$ for $2500 \mathrm{~h}$.

TEM bright-field images of the TCP phases observed in the CMSX-4 superalloy annealed at temperature $1100^{\circ} \mathrm{C}$ for $2500 \mathrm{~h}$ are shown in Fig. 3a,c. The selected area electron diffraction patterns of TCP phases reveal that they are $\mathrm{P}$ orthorhombic phase (Fig. 3b,d). Similar results have been obtained by Chmiela at al. [8], who observed $\mathrm{P}$ phase precipitates in CMSX-4 annealed at temperature $1100^{\circ} \mathrm{C}$. The presence of the $\mathrm{P}$ phase at temperature above $1000^{\circ} \mathrm{C}$ was also observed in Alloy 800 by Darolia et al. [6] and in Ru-containing single-crystal superalloy by Tan et al. [11]. It has been reported that $\mathrm{P}$ phase is more thermodynamically stable than $\sigma$ and $\mu$ phases and would exist as only phase at temperature above $1100^{\circ} \mathrm{C}[6,12]$.
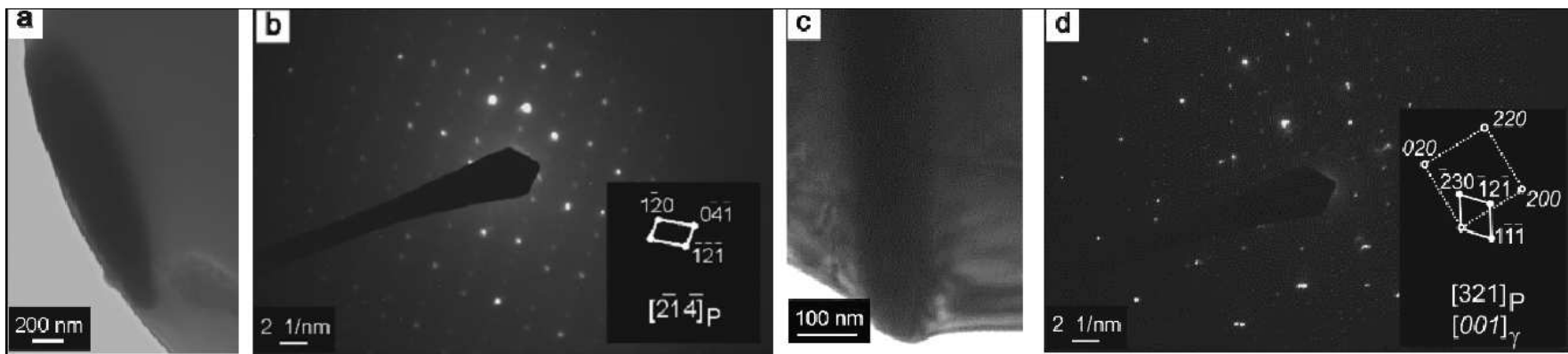

Fig. 3. TEM images (a,c) and SAED patterns (b,d) of P phase precipitates in CMSX-4 annealed at $1100{ }^{\circ} \mathrm{C}$ for $2500 \mathrm{~h}$.
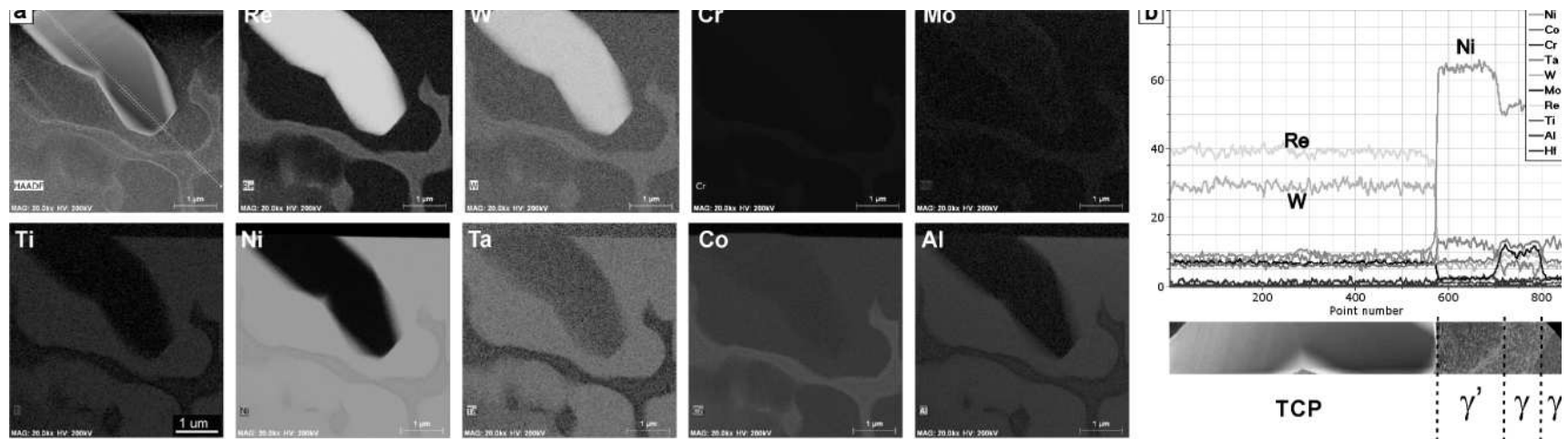

Fig. 4. (a) STEM-HAADF image of the microstructure of CMSX-4 superalloy annealed at temperature $1100^{\circ} \mathrm{C}$ for $2500 \mathrm{~h}$ and EDS elemental maps of chemical elements distribution in $\gamma, \gamma^{\prime}$ and TCP phases, (b) quantitative EDS line profiles along the line marked in (a).

Figure 4 shows the STEM-HAADF image and EDS maps of the plate-like TCP phase precipitate surrounded by the $\gamma^{\prime}$ phase as well as the wavy and isolated channels of the $\gamma$ phase. The intensity of the TCP phase in STEMHAADF image is brighter than the $\gamma$ or $\gamma^{\prime}$ phases, which suggests that it contains more heavier atoms. EDS maps show that the TCP phase precipitate contains mostly Re, W, Cr, and Mo, which are $\gamma$-phase forming elements.
The EDS data collected at individual spots along the line marked in STEM-HAADF image were visualised in the form of line profiles. Figure $4 \mathrm{~b}$ shows the concentration of the alloying elements in $\gamma, \gamma^{\prime}$ and TCP phase precipitate. It can be visible that the TCP phase particle contains mostly Re and W.

Figure 5 shows the results of the quantitative evaluation of the average chemical composition of phases exist- 
ing in the as-received CMSX-4 superalloy and annealed at temperature $1100^{\circ} \mathrm{C}$ for $2500 \mathrm{~h}$. In as-received condition the $\gamma$ phase contains more $\mathrm{Co}, \mathrm{Cr}, \mathrm{Re}$, and $\mathrm{W}$ than the $\gamma^{\prime}$ phase. After annealing at $1100^{\circ} \mathrm{C}$ the concentration of $\mathrm{Ni}, \mathrm{Ta}$, and $\mathrm{W}$ in $\gamma$ phase increases, while the amount of $\mathrm{Co}, \mathrm{Cr}, \mathrm{Mo}, \mathrm{Re}$, and $\mathrm{Al}$ decreases. The changes in the composition of the $\gamma$ and $\gamma^{\prime}$ phases are associated with the precipitation of the TCP phases, which contain mostly Re and $\mathrm{W}$ as well as smaller amounts of Ni, Co, Cr, Ta, and Mo. The mean composition of the TCP phases is the following (in wt\%): $35.9 \mathrm{Re}-30.9 \mathrm{~W}-10.3 \mathrm{Ni}-$ $7.1 \mathrm{Co}-6.9 \mathrm{Cr}-6.3 \mathrm{Ta}-0.4 \mathrm{Mo}-0.2 \mathrm{Al}$. Re and $\mathrm{W}$ are especially added for solution strengthening of the $\gamma$ phase, thus the precipitation of TCP phases is most likely associated with the weakening of the $\gamma$ matrix.

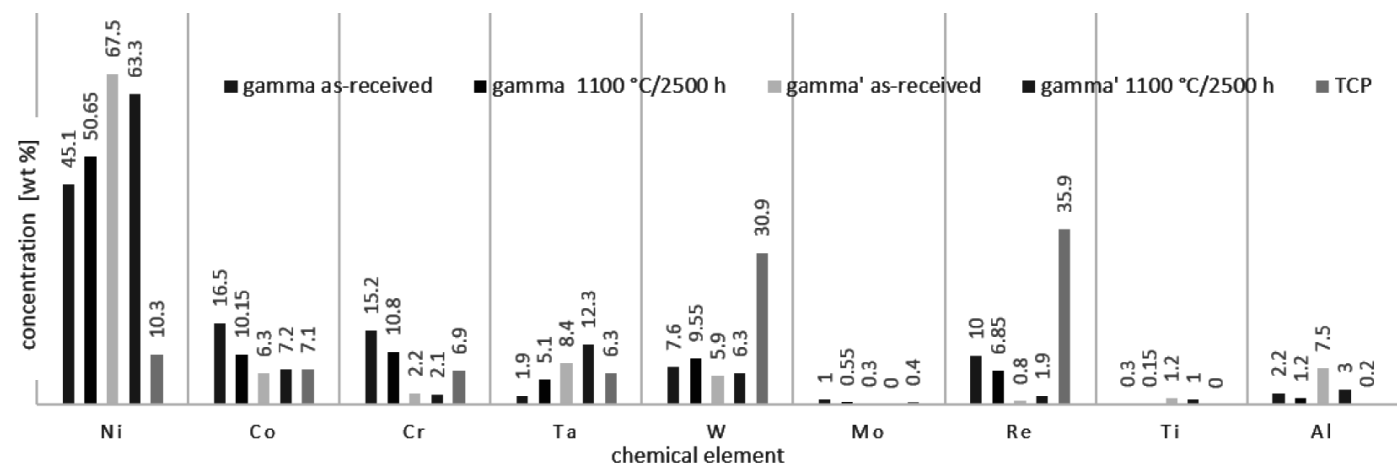

Fig. 5. Average chemical composition of phases in CMSX-4 superalloy in as received condition $\left(\gamma\right.$ and $\left.\gamma^{\prime}\right)$ and after annealing at temperature $1100^{\circ} \mathrm{C}$ for $2500 \mathrm{~h}$ determined by high spatial resolution and high efficiency EDS system.

\section{Conclusions}

1. The precipitates of TCP phases in CMSX-4 superalloy were observed even after short time annealing for $50 \mathrm{~h}$ at temperature $1100^{\circ} \mathrm{C}$. With prolongation of the annealing time up to $2500 \mathrm{~h}$ the change of the morphology of TCP particles from blocky to needle-like occurred.

2. Selected area electron diffraction analysis indicated that the needle-like TCP precipitates are the orthorhombic $\mathrm{P}$ phase.

3. Quantitative EDS analysis revealed that after annealing at temperature $1100{ }^{\circ} \mathrm{C}$ for $2500 \mathrm{~h}$ the average chemical composition of the TCP phase precipitates in CMSX-4 superalloy contains about $36 \mathrm{wt} \%$ Re and 31 wt\% W. Because Re and W are added for solution strengthening of the $\gamma$ phase, the precipitation of TCP phases is most likely associated with the deterioration of the creep strength.

\section{Acknowledgments}

This work was supported by the Polish National Science Centre, project no. 2012/07/B/ST8/03392. The authors thank Howmet Exeter, UK for providing the CMSX-4 material. We also thank Dr. Marta Gajewska from ACMiN AGH-UST for the preparation of FIB lamella used for STEM-EDS analysis.

\section{References}

[1] R.C. Reed, The Superalloys. Fundamentals and Applications, Cambridge University Press, Cambridge 2006.

[2] K. Harris, G.L. Erickson, R.E. Schwer, in: ASM Specialty Handbook: Heat-Resistant Materials, Ed. J.R. Davis, ASM International, 1997, p. 255.

[3] P. Caron, T. Khan, Aerosp. Sci. Technol. 3, 513 (1999).

[4] A.C. Yeh, S. Tin, Metall. Mater. Trans. A 37, 2621 (2006).

[5] C.M.F. Rae, M.S.A. Karunaratne, C.J. Small, R.W. Broomfield, C.N. Jones, R.C. Reed, in: Superalloys 2000, Eds. T.M. Pollock, R.D. Kissinger, R.R. Bowman, K.A. Green, M. McLean, S. Olson, J.J. Schirra, TMS, 2000, p. 767.

[6] R. Darolia, D.F. Lahrman, R.D. Field, in: Superalloys 1988, Eds. S. Reichman, D.N. Duhl, G. Maurer, S. Antolovich, C. Lund, Warrendale (PA) 1988, p. 255.

[7] N. Saunders, M. Fahrmann, C.J. Small, in Ref. [5], p. 803 .

[8] B. Chmiela, M. Sozańska, K. Rodak, Solid State Phenom. 186, 58 (2012).

[9] Kui Yu Cheng, Chang Yong Jo, Tao Jin, Zhuang Qi $\mathrm{Hu}$, J. Alloys Comp. 509, 7078 (2011).

[10] B.G. Choi, C.Y. Jo, H.U. Hong, I.S. Kim, S.M. Seo, H.M. Kim, Trans. Nonferrous Met. Soc. China 21, 1291 (2011).

[11] X.P. Tan, J.L. Liu, T. Jin, Z.Q. Hu, H.U. Hong, B.G. Choi, I.S. Kim, C.Y. Jo, Philos. Mag. Lett. 92, 556 (2012).

[12] C.M.F. Rae, R.C. Reed, Acta Mater. 49, 4113 (2001). 